\title{
Drugs approval process gets speed treatment
}

\section{Erica Klarreich, London}

The European Union (EU) is mulling over changes that could halve the average time taken to approve new drug treatments.

A proposal adopted by the European Commission (EC) on 18 July would, its supporters say, cut the average licensing time for new active substances from 18 months to about 9 months. "We want to increase the availability of new and innovative medicines on the European market," says Erkki Liikanen, the EC commissioner for enterprise.

The plan will now go to the Council of Ministers, which represents the 15 members of the EU, and to the European Parliament. Both can suggest amendments. Before it can be implemented, the plan must be approved by the council and the parliament - a process that may take several years and modify the proposals significantly.

EC officials say the new plan would make the drug approvals process in Europe faster than that in the United States - although Liikanen denies that the EC is in a race with the US Food and Drug Administration (FDA) to speed up approval."We just want to guarantee that European patients and industry have the same opportunities as anywhere else," he says.

The plan would shorten deadlines for various parts of the approval process, introducing a 'fast track' for especially promising

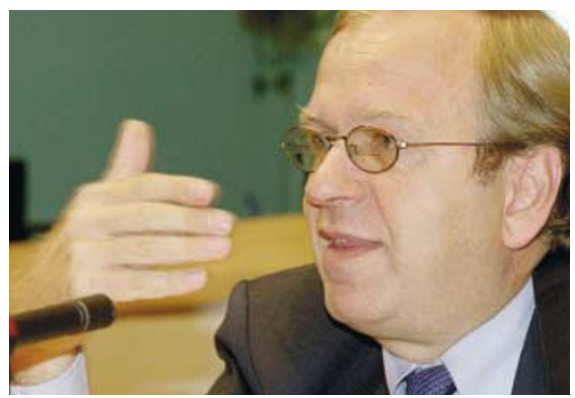

No safety compromise: Liikanen says the shortcuts would be bureaucratic, not scientific.

medicines. To streamline the process, the London-based European Agency for the Evaluation of Medicinal Products would be given much broader responsibilities. At present, drug companies can choose to go through this agency to obtain EU-wide approval for drugs containing new active substances. However, most medicines are still licensed by individual member states.

In the United States, a recent acceleration of the FDA's approval processes has been criticized by consumer groups. And some health experts warn that speeding up the European procedure may endanger patients. "Probably what will happen is that the amount of data that regulators check independently will be reduced to make deadlines," says John Abraham, director of the
Centre for Research in Health and Medicine at the University of Sussex.

A faster approval process will require the commission to spend more on licensing, draining resources from other public-health needs, says Joe Collier, a health-policy specialist at St George's Hospital Medical School in London. "The commercial arm of the European Commission has driven these changes, not the public-health arm," he says.

But Liikanen says the changes would not compromise drug safety. "The cuts will be on the bureaucratic side, not the scientific side," he says.

The pharmaceutical industry gave the plan a cautious endorsement. "Broadly speaking, we welcome efforts to approve drugs more quickly," says Richard Ley, a spokesman for the Association of the British Pharmaceutical Industry.

The commission thinks that the slow pace of approvals in Europe has driven away pharmaceutical research in recent years. Europe's share of the global pharmaceutical market has dwindled from $32 \%$ to $22 \%$ in the past decade, whereas the US share has grown from $31 \%$ to $43 \%$, according to the European Federation of Pharmaceutical Industries and Associations. But some observers say that price controls in Europe - and their absence in the United States - has provided most of the impetus for the change.

\section{Scientists fear new guidelines will stifle basic research}

\section{David Cyranoski, Tokyo}

Science-policy guidelines issued by Japanese prime minister Junichiro Koizumi have ignited a fire-storm of protest among the country's leading researchers.

The scientists are upset because they say the guidelines, which strongly emphasize the economic value of research and development, don't provide strong enough support for basic scientific research.

The guidelines were issued on 11 July by the Council for Science and Technology Policy, the top science-policy-making body in the government, which Koizumi chairs. They call for a strategic focus on four key areas of research - life sciences, information technology, environmental research and nanotechnology — and the reform of Japan's science and technology system to build industrial competitiveness, a vigorous economy, better health care and a safe environment.

But 18 former and existing heads of some of the country's leading research institutes wrote an open letter to Koizumi, stating that the guidelines will stifle basic

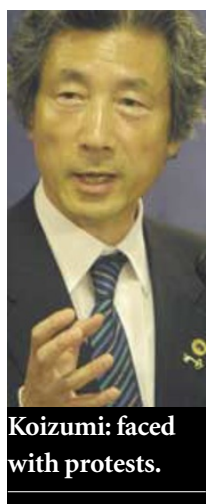

research by "completely mobilizing science and technology to meet shortterm goals aimed primarily at industrial competitiveness". According to Yoshiki Hotta, director of the National Institute of Genetics, who helped to draft the letter, researchers outside the specified fields will either lose support or "do their work under the cover of some other project that fits the government specifications. There's no clear allocation for basic science in the guidelines, and this is dangerous," he says.

A senior researcher at Tokyo University's medical school, who declined to be named, added that the guidelines "will lead to demoralization of scientists, as they keep running after whatever goal is set by the government".

The letter earned its authors a 15-minute audience with Koji Omi, a cabinet-level minister for science and technology policy, who told them that the guidelines make sufficient allowance for basic research. The guidelines state that Japan should "achieve international-class, high-quality basic research that will clear a path to the future". But critics say such words merely pay lip-service to the problem.

Hotta says that the group wrote the open letter - a dramatic gesture by Japanese standards - because there is no proper channel for scientists to give their opinions to the government. Many researchers criticize the Council for Science and Technology Policy for failing to represent their views. The council is composed mostly of ministers and industry representatives, and researchers say that the three academic scientists on it have limited influence.

Some industrialists echo the scientists' complaints. The government has "no clear understanding of what the best research is — and yet they want to move on to application," says Toshiaki Ikoma, president of Texas Instruments in Japan. 